\title{
The ablation zone in northeast Greenland: ice types, albedos and impurities
}

\author{
Carl Egede BØGGILD, ${ }^{1}$ Richard E. BRANDT, ${ }^{2}$ Kendrick J. BROWN, ${ }^{3,4,5}$ \\ Stephen G. WARREN ${ }^{2}$ \\ ${ }^{1}$ The University Centre in Svalbard (UNIS), Box 156, NO-9171 Longyearbyen, Norway \\ E-mail: carl.egede.boggild@unis.no \\ ${ }^{2}$ Department of Atmospheric Sciences, University of Washington, Seattle, Washington 98195-1640, USA \\ ${ }^{3}$ Canadian Forest Service, Northern Forestry Centre, 5320 122nd Street, Edmonton, Alberta T6H 3S5, Canada \\ ${ }^{4}$ Geological Survey of Denmark and Greenland, Oster Voldgade 10, DK-1350 Copenhagen, Denmark \\ ${ }^{5}$ Royal British Columbia Museum, 675 Belleville Street, Victoria, British Columbia V8W 9W2, Canada
}

\begin{abstract}
Ice types, albedos and impurity content are characterized for the ablation zone of the Greenland ice sheet in Kronprinz Christians Land $\left(8^{\circ} \mathrm{N}, \mathbf{2 4}^{\circ} \mathrm{W}\right)$. Along this ice margin the width of the ablation zone is only about $8 \mathrm{~km}$. The emergence and melting of old ice in the ablation zone creates a surface layer of dust that was originally deposited with snowfall high on the ice sheet. This debris cover is augmented by locally derived wind-blown sediment. Subsequently, the surface dust particles often aggregate together to form centimetre-scale clumps that melt into the ice, creating cryoconite holes. The debris in the cryoconite holes becomes hidden from sunlight, raising the area-averaged albedo relative to surfaces with uniform debris cover. Spectral and broadband albedos were obtained for snow, ice hummocks, debris-covered ice, cryoconite-studded ice and barren tundra surfaces. Broadband ice albedos varied from 0.2 (for ice with heavy loading of uniform debris) to 0.6 (for ice hummocks with cryoconite holes). The cryoconite material itself has albedo 0.1 when wet. Areal distribution of the major surface types was estimated visually from a transect video as a function of distance from the ice edge ( $330 \mathrm{~m}$ a.s.l.). Ablation rates were measured along a transect from the ice margin to the slush zone $8 \mathrm{~km}$ from the margin $(550 \mathrm{~m}$ a.s.l.), traversing both Pleistocene and Holocene ice. Ablation rates in early August averaged $2 \mathrm{~cm} \mathrm{~d}^{-1}$. Impurity concentrations were typically $4.3 \mathrm{mg} \mathrm{L}^{-1}$ in the subsurface ice. Surface concentrations were about $16 \mathrm{~g} \mathrm{~m}^{-2}$ on surfaces with low impurity loading, and heavily loaded surfaces had concentrations as high as $1.4 \mathrm{~kg} \mathrm{~m}^{-2}$. The mineralogical composition of the cryoconite material is comparable with that of the surrounding soils and with dust on a snowdrift in front of the ice margin, implying that much of the material is derived from local sources. A fine mode (clay) is present in the oldest ice but not in the nearby soil, suggesting that its origin is from wind deposition during Pleistocene glaciation.
\end{abstract}

\section{INTRODUCTION}

The Greenland ice sheet is experiencing thickening of the interior accumulation area (Zwally and others, 2005), thinning of the marginal ablation area (Krabill and others, 2004) and acceleration of large outlet glaciers that calve into fjords around the southern half of the island (Rignot and Kanagaratnam, 2006). At land-based margins, where melting is the major mass-loss process, recent observations show an acceleration of ice motion in summer, partly due to lubrication of the bed associated with meltwater (Zwally and others, 2002). If melting rates were unchanged, this increase in velocity would result in an advance of the icesheet margin or an increase in surface height. However, such changes have not been seen, suggesting that the increase in ice flow is accompanied by an increase in melt rates. Recent meteorological and modelling studies likewise suggest enhanced melting in the ablation zone (Hanna and others, 2005; Box and others, 2006).

The major source of energy for melting ice and snow is provided by shortwave radiation. Therefore, melting rates in the ablation area are largely determined by the albedo of the ice, which is lower than that of snow and also highly variable. The variability is due to variable debris cover on the ice, and variable fractional coverage of the ice by meltwater ponds. In 1960, the ablation area covered $\sim 15 \%$ of the icesheet area (Benson, 1960; Bader, 1961). Climatic warming is expected to cause an expansion of the ablation area at the expense of the accumulation area. The reduction in albedo caused by removal of snow cover and consequent exposure of bare ice results in a positive feedback to climate change. Therefore, it is important to characterize the albedos of the ablation zone and to assess the reasons for their variability.

The temporal evolution of the surface reflectance of the ablation zone in west Greenland has been studied previously using a combination of satellite analyses and data from automatic weather stations (AWSs). The ice-sheet margin east of Søndre Strømfjord (Kangerlussuaq) shows that a darkening of the glacier ice surface takes place in the upper ablation zone late in the summer (Knap and Oerlemans, 1996; Greuell, 2000). This late-summer dark zone is also seen on other parts of the ice-sheet margin (e.g. south Greenland (Weidick, 1995) and northeast Greenland (Oerter and others, 1995; Bøggild and others, 1996; Bøggild, 1998)). The dark upper ablation zone of west Greenland, described by Knap and Oerlemans (1996), appears to extend continuously for $>500 \mathrm{~km}$ in the north-south direction, as seen 


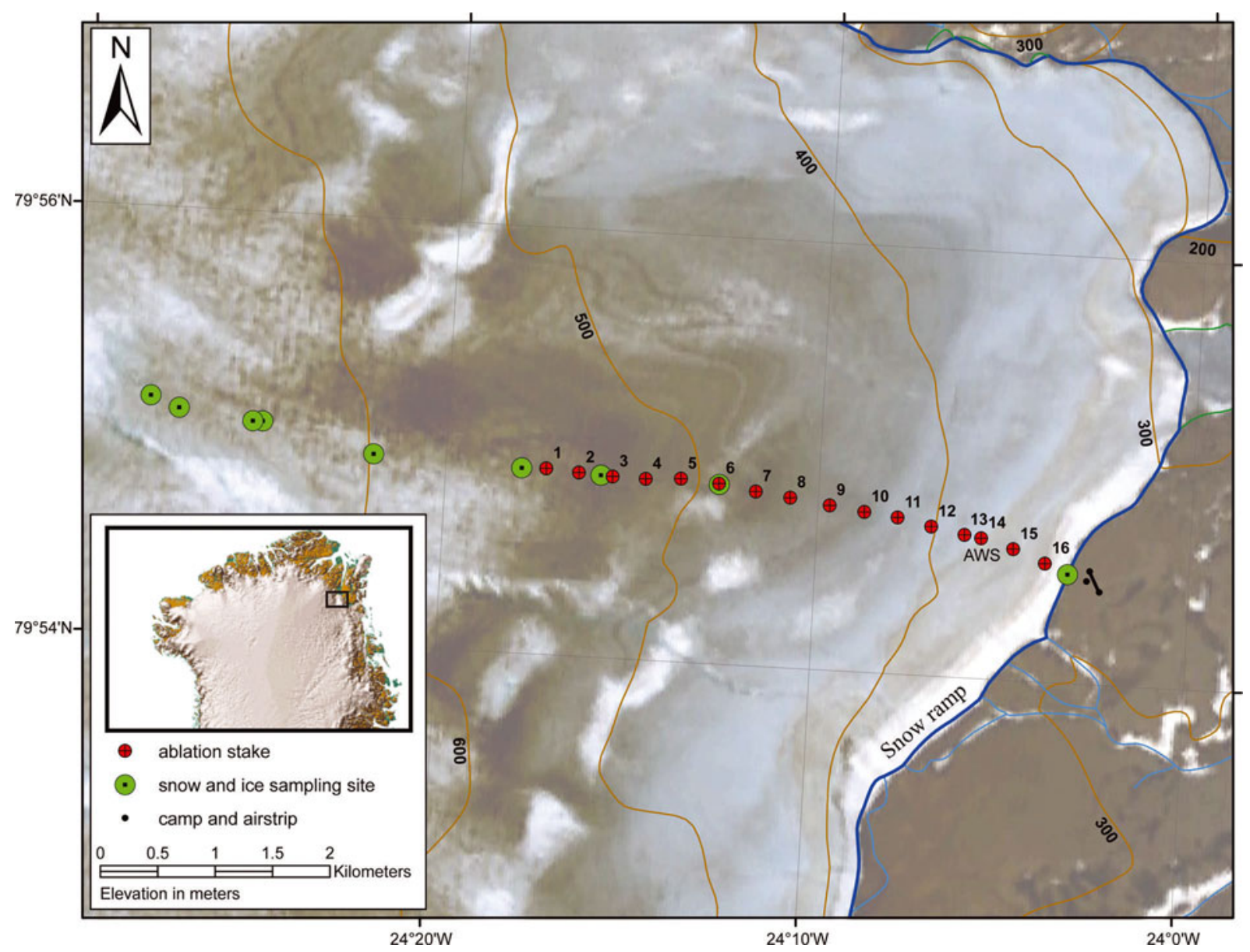

Fig. 1. Landsat image of the research area, with elevation contours $(\mathrm{m})$ and identification of ablation stakes and sites where snow and ice were sampled for impurity analysis by Nuclepore filtration. The boundary between Pleistocene and Holocene ice on the surface is near stake 14. The image was acquired from Landsat 7 on 4 July 2000 (WRS-2, path 009, row 003, online 042-7874). The image is a composite of Landsat bands 1, 2 and 3, covering wavelengths 450-520, 520-600 and 630-690 nm respectively. Source for this dataset was the Global Land Cover Facility, College Park, Maryland, USA.

by Holmlund and Jansson (2003, p. 86). With climatic warming, a rising equilibrium line could expose new areas of the dark upper ablation zone and thus further advance the melting and thinning of the Greenland ice sheet. Based on Advanced Very High Resolution Radiometer (AVHRR) satellite images, Greuell (2000) and Greuell and Knap (2000) attributed the low albedo of the dark zone to surface meltwater. In our study, however, the dark upper ablation zone lacks meltwater ponds, and the low albedo is instead caused mainly by particulates on the surface.

This phenomenon may be related to the behaviour of mineral dust in the ice, particularly whether it remains uniformly distributed. The surface dust particles often aggregate together to form centimetre-scale clumps ('cryoconite') that melt into the ice, creating 'cryoconite holes' (Kayser, 1928; Lliboutry, 1964). The debris in the cryoconite holes thus becomes partly hidden from sunlight, raising the area-averaged albedo relative to surfaces with uniform debris cover.

Measurements on the ice-sheet surface are logistically difficult in many areas because of the crevassed nature of much of the marginal zone, and because of the great width, $50-100 \mathrm{~km}$, of the ablation zone in west Greenland. However, ablation-zone processes can readily be studied in parts of northeast Greenland, where the ablation zone is only $5-8 \mathrm{~km}$ wide and not crevassed. The dark upper ablation zone seen in west Greenland is also found in northeast Greenland. In 2006 we carried out surface observations and measurements of the glacier surface in northeast Greenland, including characterization of the ice types, measurement of spectral albedo, and identification and quantification of impurities.

\section{FIELD EXPERIMENT}

A field camp at the ice margin in Kronprinz Christians Land (KPCL), near $80^{\circ} \mathrm{N}, 24^{\circ} \mathrm{W}$ (Fig. 1), was occupied from 26 July to 12 August 2006. This is the same location that was studied by Konzelmann and Braithwaite (1995), Bøggild and others (1996) and Bøggild (1998). Access was by Twin Otter aircraft from Station Nord, $240 \mathrm{~km}$ to the northeast. The ice sheet terminates in a cliff, as is usual for cold-based glaciers. But because of katabatic winds, the cliff was buried by drift snow in many places, providing a 'ramp' for easy access on foot to the ice. A sampling transect consisting of ablation stakes and the collection of snow and ice samples was established across the ablation zone (Fig. 1).

An AWS was operated for 6 days (5-10 August) at stake 14, at the Pleistocene/Holocene transition, about $1 \mathrm{~m}$ above a hummocky ice surface. At night and in early morning the average air temperature was $-2{ }^{\circ} \mathrm{C}$, the dew-point depression 
$1-2 \mathrm{~K}$ and downward solar irradiance $0-30 \mathrm{Wm}^{-2}$. At midday or in the afternoon the temperature rose to $1-4^{\circ} \mathrm{C}$, the dew-point depression to $5 \mathrm{~K}$ and the solar irradiance to 400-600 $\mathrm{W} \mathrm{m}^{-2}$.

\section{THE ICE SURFACE}

In Figure 1, the brown band just above the snow ramp is Pleistocene ice of 'Wisconsin' age (Bøggild and others, 1996). Blue ice of early Holocene age is located above the Pleistocene ice, followed by the darker band of the upper ablation zone, which becomes snow-covered at the higher elevations, as seen in the northwest corner of Figure 1. In Figure 1 the Holocene/Pleistocene transition shows a color contrast but not a brightness contrast. Analyses of ice cores from the interior of Greenland have shown higher dust content during the Last Glacial Maximum than during the Holocene (De Angelis and others, 1997). However, at this location the Pleistocene ice actually contains less debris than the Holocene ice, for unknown reasons. We therefore present our work primarily as a process study, particularly regarding the effects of cryoconite-hole formation on albedo.

Figure 2a shows the elevations along the ablation-stake transect. The elevation gradients are near constant except for the cliff at the ice edge, which was hidden by the snow ramp. The mean slope is $4.2 \%$, which is smaller than that of most valley glaciers but quite common in the ablation zone of the Greenland ice sheet (Weidick and others, 1992).

Characterization of the surface was accomplished using a continuous scan from a video camera oriented vertically downward. The camera was mounted on a horizontal bar at $1.65 \mathrm{~m}$ above the surface and carried manually for the length of the transect. Stakes of known location were tagged on the recording to convert from time to distance. Processing involved visual analysis of still images at $30 \mathrm{~m}$ intervals along the entire transect, where a percentage distribution was estimated for five classes of surface types, shown in Figure 2b: superimposed ice (Paterson, 1994, fig. 2.1), low-impurity ice, intermediate-impurity ice, highimpurity ice, and ice with cryoconite holes. Since snow cannot be distinguished from superimposed ice in the video images, these two surface types are merged into one class in Figure 2b. Ice with cryoconite holes can be distinguished clearly from other surface types, but the distinction of the three classes of uniformly distributed impurity is subjective. In addition to the surface types indicated in Figure $2 b$, there are meltwater streams, but from our photographs on a helicopter flight we estimate that they covered only $1-2 \%$ of the surface area of the ablation zone.

Much of the ice, particularly the ice studded with cryoconite holes, was hummocky. A typical well-defined 'hummock' in KPCL is 1-3 $\mathrm{m}$ in lateral extent and rises up to $1 \mathrm{~m}$ above the general surface of its surroundings (right side of Fig. 3a). Hummocks were prevalent in the first $2 \mathrm{~km}$ from the ice edge, but sparse beyond $2 \mathrm{~km}$.

In Figure 3a, ice with intermediate and high impurity content is seen in the foreground; cryoconite holes are absent. In the left background a surface of low impurity content is dominant; in the right background are hummocks. In Figure $3 \mathrm{~b}$ a low-impurity surface and an adjoining hummock are shown in a vertical view. The hummock has well-defined cryoconite holes. The superimposed ice or

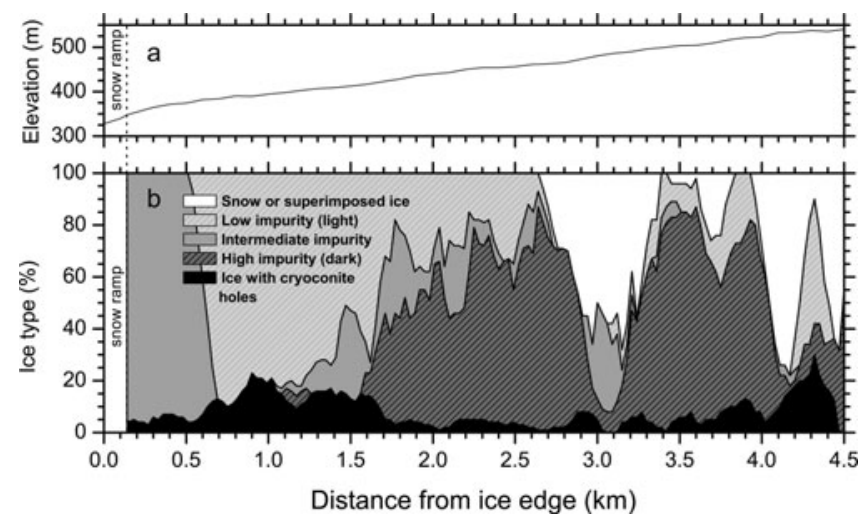

Fig. 2. Characteristics of the ablation zone as functions of distance from the ice edge. (a) Elevation above sea level, from hand-held GPS at $100 \mathrm{~m}$ intervals. (b) Percent coverage of different ice types, from visual analysis of images from a nadir-looking video camera held at $1.65 \mathrm{~m}$ height, with a field of view $1 \mathrm{~m}$ diameter. Images were analyzed every $30 \mathrm{~m}$ along the transect; a $120 \mathrm{~m}$ running mean is shown here.

snow surfaces are often delineated by characteristic steep edges of $10 \mathrm{~cm}$ height (Fig. 3c). In the upper part of the transect, especially from 3.5 to $4 \mathrm{~km}$, concentrations of impurities on the surface form poorly confined 'cryoconite patches' (Fig. 3d) in an area where superimposed ice is also common. The extensive 'ice with cryoconite holes' in the lower part of the transect (Fig. 2b; 0.7-1.7 km) has a different appearance, since here the impurity is localized at the bottom of well-defined holes.

On valley glaciers the material forming cryoconite holes is often sand or pebbles, but on the ablation zone of the cold-based ice of KPCL it is only a fine powder of micronsize dust particles, which, although unconsolidated, does become concentrated in holes. This characteristic powder is similar to that described for the Thule area of northwest Greenland (Gajda, 1958). Well-defined cryoconite holes with a sharp edge and containing a free water surface above the cryoconite surface are most common in the lower half of the transect, except in the Pleistocene ice. Figure 4 shows that the deepest cryoconite holes $(20-30 \mathrm{~cm}$ deep) are to be found in the early Holocene ice, 0.6$1.5 \mathrm{~km}$ from the ice edge. This is also where the water level is deepest. In the transition from Pleistocene ice at $0.5 \mathrm{~km}$ to Holocene ice at $0.7 \mathrm{~km}$, the depth of the holes doubles, and this change of depth is also clearly visible on the glacier surface.

It is known from ice-core studies that the Pleistocene ice has smaller crystal diameters than Holocene ice, 2-3 mm vs 3-4 mm (Thorsteinsson and others, 1997, fig. 2). Bøggild (1998) interpreted the variable depth of cryoconite holes as being a result of difference in radiation penetration; the smaller crystal size in Pleistocene ice results in a larger scattering coefficient and therefore a shallower hole. A cryoconite hole will reach an equilibrium depth such that the melting rate at the bottom of the hole equals that of the surrounding clean ice (Gribbon, 1979). If the energy for melting is dominated by solar radiation, then the rates of solar absorption would be equal at the two surfaces. Ice with smaller grains would have a larger flux-extinction coefficient and a shallower hole depth.

Because cryoconite holes are narrow and vertical, the cryoconite material in them is seen only when looking very 

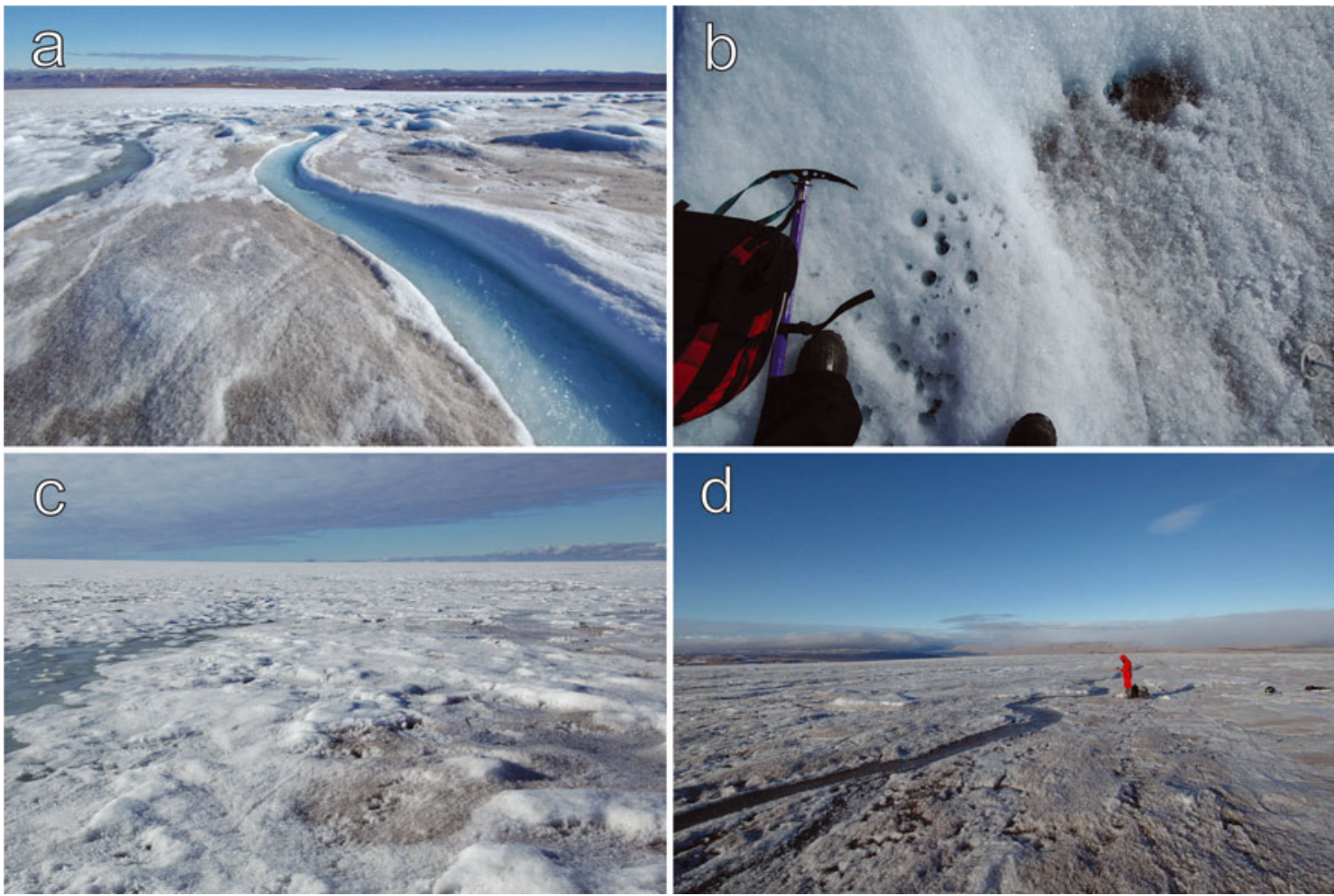

Fig. 3. Examples of surface types. (a) Pleistocene ice with uniform debris cover (i.e. no cryoconite holes) and meltwater streams, near stake 15. Hummocks are in the intermediate background on the right; barren tundra is in the distance. (b) Cryoconite holes in a hummock on the left, bordering ice with mostly uniform debris cover on the right, near stake 15. (c) Slush and superimposed ice near the equilibrium line, $8 \mathrm{~km}$ from the ice edge, at the location marked by the westernmost green dot in Figure 1. (d) Ice with heavy loading of debris in the upper ablation zone, near stake 3 .

close to nadir. This causes some satellites (e.g. Landsat), which view in the nadir direction, to be biased darker in regions of cryoconite holes. Oblique views, in which the cryoconite is hidden, will more accurately represent the hemispherically averaged albedo.

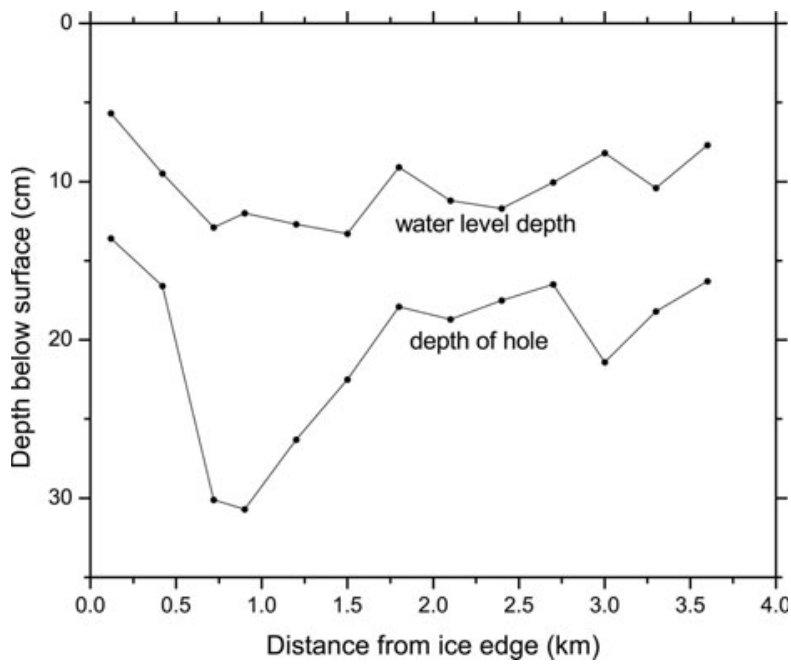

Fig. 4. Depth of cryoconite holes (vertical distance from the edge of the hole down to the cryoconite material on the bottom of the hole) as a function of distance from the ice edge. The water level within the holes is also shown. The thickness of the cryoconite material itself was only a few mm, a small fraction of the depth of the hole.

\section{SPECTRAL AND BROADBAND ALBEDOS}

Albedo $(\alpha)$ as a function of wavelength $(\lambda)$ was measured with a spectral radiometer, manufactured by Analytical Spectral Devices (ASD; Kindel and others, 2001), equipped with a fiber-optics guide viewing a diffuser plate. The diffuser plate was levelled horizontally to view the sky, then rotated $180^{\circ}$ to view the surface. The instrument measures radiation every $1 \mathrm{~nm}$ from $0.35 \mu \mathrm{m}$ in the near-ultraviolet (near-UV), across the visible $(0.4-0.7 \mu \mathrm{m})$, to $2.5 \mu \mathrm{m}$ in the near-infrared (near-IR), with a spectral resolution of 3-30 nm (full width at half-maximum). For most of our measurements, there was insufficient signal at $\lambda>1.8 \mu \mathrm{m}$ to measure albedo, because of low light levels at higher wavelengths.

Spectral albedos were measured for the various surface types in the ablation zone (Fig. 5). The general shape of the top five curves is similar to that of snow (Grenfell and others, 1994) and sea ice (Grenfell and Perovich, 1984; Brandt and others, 2005). The peaks and valleys in the near-IR spectrum $(\lambda>0.7 \mu \mathrm{m})$ correspond to local minima and maxima of the absorption coefficient of pure ice (Grenfell and Perovich, 1981; Warren and Brandt, 2008).

All the ice types show albedo increasing with wavelength from $\lambda=0.35 \mu \mathrm{m}$ (near-UV) to $0.6 \mu \mathrm{m}$ (red), because of the presence of dust in the ice, which is red or brown because it contains iron oxides which absorb strongly in the blue and ultraviolet (UV). The Pleistocene ice is more strongly redcolored (has a steeper slope of $\alpha$ vs $\lambda$ ) than the Holocene ice; this coloring is also apparent in Figure 1.

The albedo of ice with a uniform debris cover on the surface, whether light, intermediate or dark, is much lower 


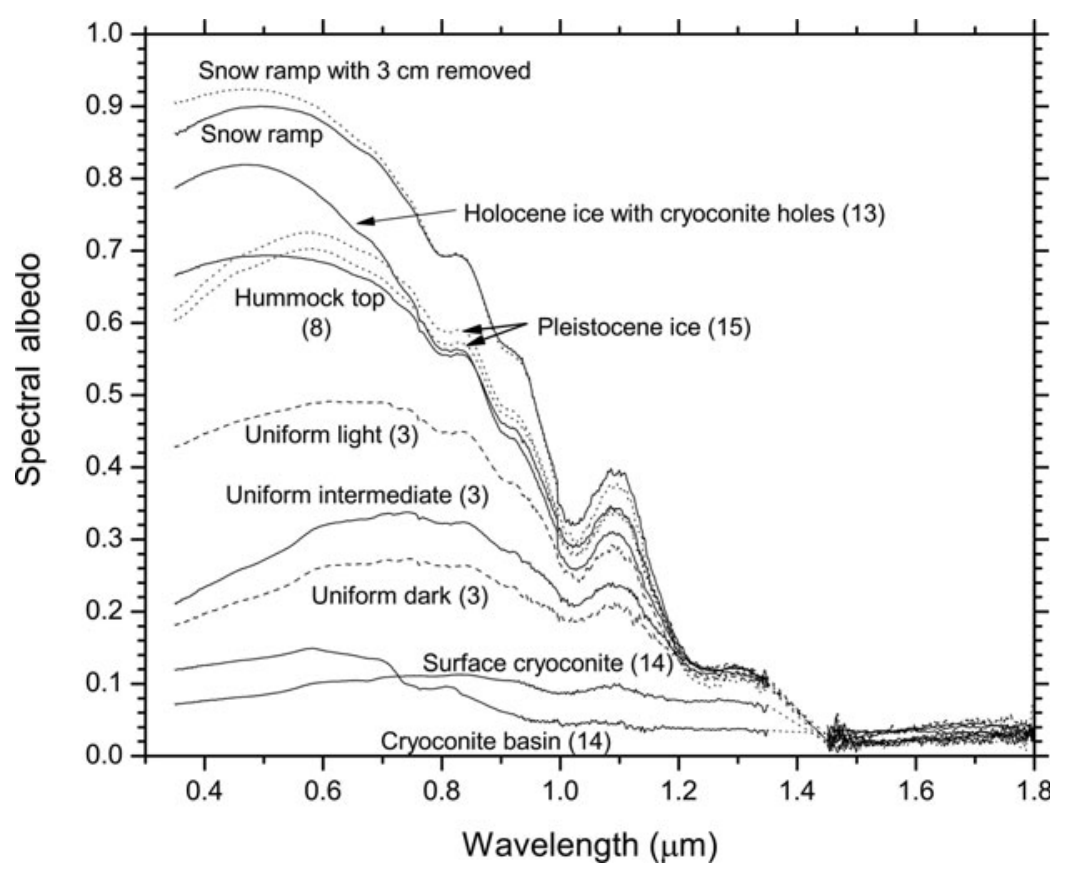

Fig. 5. Spectral albedos of ice types in the ablation zone. The locations are indicated by the nearest stake number, in parentheses (see Fig. 1). Broadband albedos for these ice types are given in Table 1. Three curves are shown for ice covered uniformly with three different debris loadings: light, intermediate and dark. The peculiar spectral shape of the cryoconite-basin albedo is explained in Figure 7 . From 1.35 to $1.45 \mu \mathrm{m}$ wavelength, albedo measurement was not possible because the incident solar radiation flux was near zero at these wavelengths; the dashed curves interpolate across this region.

than that of ice with cryoconite holes, in spite of the fact (discussed below) that ice with cryoconite holes has a greater impurity loading (mass per unit area). This is because the descent of debris into holes hides it from sunlight so that most of the solar radiation interacts only with the relatively clean upper ice above the cryoconite. A second effect is that aggregation of the dust into clumps lessens its absorptive capability even if it remains on the surface, because the albedo-lowering effect of dust is greatest if the dust is spread uniformly. The ice with uniform debris cover also tends to be waterlogged, i.e. its water table is much higher than those shown in Figure 4 . This high water table also contributes to the lowering of albedo in regions of uniform debris cover, by reducing the scattering at ice crystal boundaries. The high water table itself may be caused by the inability of the slow drainage to outrun the rapid ablation at low albedo, i.e. a positive feedback on ablation rate.

Most cryoconite holes have diameters of a few millimeters to a few centimeters, but some very wide holes also form, whose widths can exceed their depth (Sharp, 1949; Gajda, 1958; Gerdel and Drouet, 1960). Sharp called these wide holes 'dust basins'; we call them 'cryoconite basins'. We measured the spectral albedo of a meter-sized basin of depth $\sim 15 \mathrm{~cm}$, whose ice floor was completely covered by a few millimeters of fine-grained cryoconite material, which in turn was covered by water. Nearby a drained cryoconite basin exposed an extensive cryoconite layer that was damp but not covered by water. These two surface types are the darkest surfaces in the ablation zone (lowest curves in Fig. 5).

Broadband solar albedos $(\bar{\alpha})$ were computed from the measured spectral albedos together with a modeled incident solar spectral irradiance $S(\lambda)$ :

$$
\bar{\alpha}=\frac{\int \alpha(\lambda) S(\lambda) \mathrm{d} \lambda}{\int S(\lambda) \mathrm{d} \lambda} .
$$

The solar spectral irradiance was obtained using the atmospheric radiation model 'ATRAD' (Wiscombe and others, 1984) for the subarctic summer standard atmosphere of McClatchey and others (1972), which had been computed for a solar zenith cosine of 0.4 (zenith angle $66^{\circ}$ ), both for clear sky and for overcast cloud of optical depth 11, typical of Arctic summer stratus clouds (Herman and Curry, 1984; Tsay and Jayaweera, 1984).

The limits of integration in Equation (1) are $0.3-4.0 \mu \mathrm{m}$, covering the solar energy spectrum at the surface, but most of our albedo measurements are available only from 0.35 to $1.8 \mu \mathrm{m}$. To complete the integration, the following assumptions were used. At the shortwave end, the UV albedo from 0.30 to $0.35 \mu \mathrm{m}$ was assumed the same as at $0.35 \mu \mathrm{m}$. At the longwave end, the albedo from 1.8 to $4.0 \mu \mathrm{m}$ is very low for all types of ice. Two limiting cases were computed: $\alpha(\lambda>1.8 \mu \mathrm{m})=\alpha(1.8 \mu \mathrm{m})$, and $\alpha(\lambda>1.8 \mu \mathrm{m})=0$. Because $<3 \%$ of the solar energy is at $\lambda>1.8 \mu \mathrm{m}$, the two limiting values of broadband albedo differed insignificantly.

The resulting broadband albedos are given in Table 1. Included in Table 1 is the albedo of the snow ramp. The particulate impurities were concentrated in the topmost $3 \mathrm{~cm}$ of the snow. When this layer was removed, the albedo of the remaining snow was higher in the visible wavelengths but lower in the near-IR (Fig. 5), indicating that the lower layer had both fewer impurities and coarser grains. The two effects compensate each other, causing the broadband albedos to be almost identical for the two snow layers.

These measured albedos for particular ice types in Table 1 may be compared with broadband albedos from prior work at this location as well as in the ablation zone of west Greenland (Table 2). Table 2 shows that the albedo of melting glacier ice is generally in the range 0.5-0.6, but for superimposed ice it is $\sim 0.68$, nearly as high as for ice covered by melting snow $(\sim 0.70)$. Darker regions have 
Table 1. Broadband solar albedos for characteristic ice types in the ablation zone of northeast Greenland, and nearby tundra surfaces $\left(80^{\circ} \mathrm{N}, 24^{\circ} \mathrm{W}\right)$, in August 2006. The spectral albedos from Figures 5 and 6 were integrated over wavelength, weighted by the solar spectral irradiance computed using an atmospheric radiation model (Wiscombe and others, 1984) for the subarctic summer standard atmosphere (McClatchey and others, 1972), and a solar zenith angle of $66^{\circ}$. Two values are given for each surface type: albedo under clear sky, and albedo under an overcast cloud with optical depth 11 and base height $700 \mathrm{~m}$, characteristic of Arctic summer stratus (Herman and Curry, 1984; Tsay and Jayaweera, 1984). The lack of spectral albedo measurement beyond $1.8 \mu \mathrm{m}$ wavelength causes an uncertainty of $<0.001$ in broadband albedo (see text)

\begin{tabular}{|c|c|c|}
\hline \multirow{2}{*}{ Surface type } & \multicolumn{2}{|c|}{ Broadband albedo } \\
\hline & $\begin{array}{l}\text { Under } \\
\text { clear sky }\end{array}$ & $\begin{array}{c}\text { Under } \\
\text { overcast } \\
\text { cloud }\end{array}$ \\
\hline Pleistocene ice with uniform debris & 0.52 & 0.58 \\
\hline Holocene ice with cryoconite holes & 0.57 & 0.65 \\
\hline \multicolumn{3}{|l|}{ Holocene ice with uniform debris } \\
\hline Light & 0.40 & 0.44 \\
\hline Intermediate & 0.28 & 0.30 \\
\hline Dark & 0.21 & 0.22 \\
\hline Cryoconite material (damp) & 0.09 & 0.09 \\
\hline Cryoconite basin & 0.10 & 0.11 \\
\hline Natural tundra surface (rocks and soil) & 0.18 & 0.16 \\
\hline \multicolumn{3}{|l|}{ Tundra soil with large rocks removed } \\
\hline Dry & 0.23 & 0.21 \\
\hline Damp & 0.15 & 0.14 \\
\hline \multicolumn{3}{|l|}{ Snow ramp (coarse-grained melting snow) } \\
\hline Undisturbed & 0.67 & 0.75 \\
\hline After removal of debris-laden snow (top $3 \mathrm{~cm}$ ) & 0.68 & 0.76 \\
\hline
\end{tabular}

albedos in the range $0.3-0.45$; these low albedos were attributed to the presence of surface water and/or debris loading.

In Figure 6 we compare the albedo of glacial cryoconite material (from Fig. 5) with that of nearby tundra surfaces (actually 'polar desert'; Serreze and Barry, 2005). The natural tundra surface in front of the ice sheet consisted almost entirely of soil and rocks, with very little vegetation. The larger rocks were removed from an area $4 \mathrm{~m}$ in diameter, and the spectral albedo of the dry soil was measured. Water was then sprinkled onto the area, and the albedo remeasured (the dampened soil is shown in the inset image in Fig. 6). At $\lambda<0.6 \mu \mathrm{m}$, all five surfaces have similar albedo. In the nearIR the wet surfaces (surface cryoconite and cryoconite basin) have much lower albedo because water absorbs strongly in the near-IR. Damp soil has lower albedo than dry soil not only in the near-IR, but also in the visible, where water is transparent. The reason for the darkening of soil by water at visible wavelengths (shown in the inset image in Fig. 6) was explained by Twomey and others (1986) and Bohren (1987): the refractive index of clay minerals is closer to that of water than to that of air (visible refractive indices are approximately $1.5,1.3,1.0$ respectively), so the refraction at a soilwater interface occurs at a smaller angle than at a soil-air interface. Sunlight therefore penetrates deeper into wet soil and passes through more soil grains before escaping, thus increasing the probability of absorption. The characteristics we see here, with red albedo higher than blue albedo, and albedo reduction at all wavelengths upon wetting, is typical of soils (Condit, 1970). Our broadband albedo for tundra agrees with the value $\alpha \approx 0.2$ given by Duynkerke and Van den Broeke (1994), which was cited by Van den Broeke and others (2008) as $\alpha \approx 0.18$.

The 'cryoconite basin' albedo shown in Figures 5 and 6 is anomalous in that it crosses the other curves. It can be explained as a combination of several contributions, including drained white ice in the periphery of the field of

Table 2. Prior published values of broadband ice albedo in Greenland ablation zones

\begin{tabular}{|c|c|c|c|c|}
\hline Source & Location & Time & Albedo & Comment \\
\hline \multicolumn{5}{|l|}{ Northeast Greenland } \\
\hline \multirow{3}{*}{$\begin{array}{l}\text { Bøggild and others } \\
\text { (1996, fig. 3e) }\end{array}$} & KPCL, same as in this work & July & $0.3-0.5$ & Pleistocene ice \\
\hline & & & 0.55 & Early Holocene ice \\
\hline & & & 0.3 & $\begin{array}{l}\text { Young Holocene ice } \\
\text { (upper ablation zone) }\end{array}$ \\
\hline Braithwaite (1995, fig. 5) & & & $0.48-0.57$ & 'Light' Pleistocene ice \\
\hline \multicolumn{5}{|l|}{ West Greenland } \\
\hline Ambach and Markl (1983) & $70^{\circ} \mathrm{N}, 47^{\circ} \mathrm{W}$ (1850 ma.s.I.) & Summer & 0.58 & $\begin{array}{l}\text { Cited by Greuell and } \\
\text { Konzelmann (1994) }\end{array}$ \\
\hline $\begin{array}{l}\text { Henneken and others } \\
(1994 \text {, fig. 8) }\end{array}$ & $\begin{array}{c}67^{\circ} \mathrm{N}, 49^{\circ} \mathrm{W}(1500 \mathrm{~m} \text { a.s.l. }) \\
\text { near Kangerlussuaq }\end{array}$ & 17 July & 0.68 & Likely superimposed ice \\
\hline \multirow[t]{2}{*}{$\begin{array}{l}\text { Van de Wal and others } \\
(1995 \text {, fig. } 4 a)\end{array}$} & $\begin{array}{c}\text { Lower ablation zone (300-500 m a.s.I.) } \\
\text { near Kangerlussuaq }\end{array}$ & June-July & $0.5-0.6$ & $\begin{array}{l}\text { Albedo steady at } 0.5-0.6 \\
\text { throughout } 2 \text { months }\end{array}$ \\
\hline & Upper ablation zone (1017 m a.s.I.) & & 0.3 & \\
\hline \multirow{3}{*}{$\begin{array}{l}\text { Knap and Oerlemans } \\
(1996, \text { fig. } 2 \text { b) }\end{array}$} & $67^{\circ} \mathrm{N}$ near Kangerlussuaq & June-August & $0.50-0.52$ & Near margin \\
\hline & & & $\begin{array}{l}0.45 \text {, dropping to } 0.3 \\
\text { by } 20 \text { July }\end{array}$ & 1000 m elevation in 'dark band' \\
\hline & & & 0.68 & $1500 \mathrm{~m}$, probably superimposed ice \\
\hline \multirow{2}{*}{$\begin{array}{l}\text { Van den Broeke and others } \\
(2008 \text {, fig. } 4 \text { b) }\end{array}$} & $67^{\circ} \mathrm{N}$ near Kangerlussuaq & June, August & 0.56 & AWSs \\
\hline & & July & 0.54 & \\
\hline
\end{tabular}




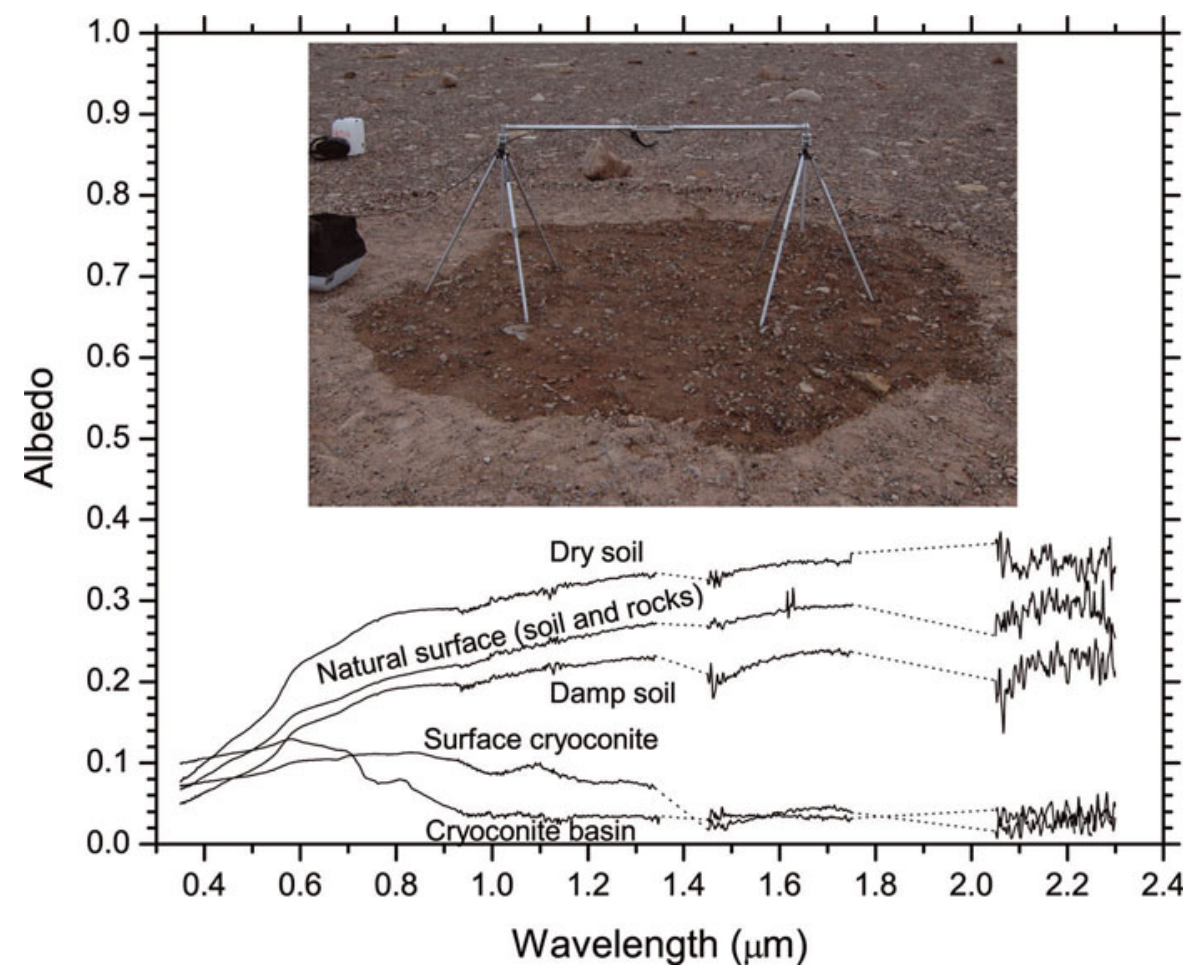

Fig. 6. Spectral albedos of cryoconite material, compared with tundra surfaces. The 'surface cryoconite' and 'cryoconite basin' spectra are the same as in Figure 5. Albedo measurements were not possible from 1.35 to $1.45 \mu \mathrm{m}$, and from 1.75 to $2.05 \mu \mathrm{m}$, because the incident solar radiation flux was near zero at these wavelengths; the dashed lines interpolate across these regions. Broadband albedos for these surfaces are given in Table 1. The inset photograph shows the fiber optic and diffuser plate of the photometer making the 'damp soil' measurement; natural surface is in the background.

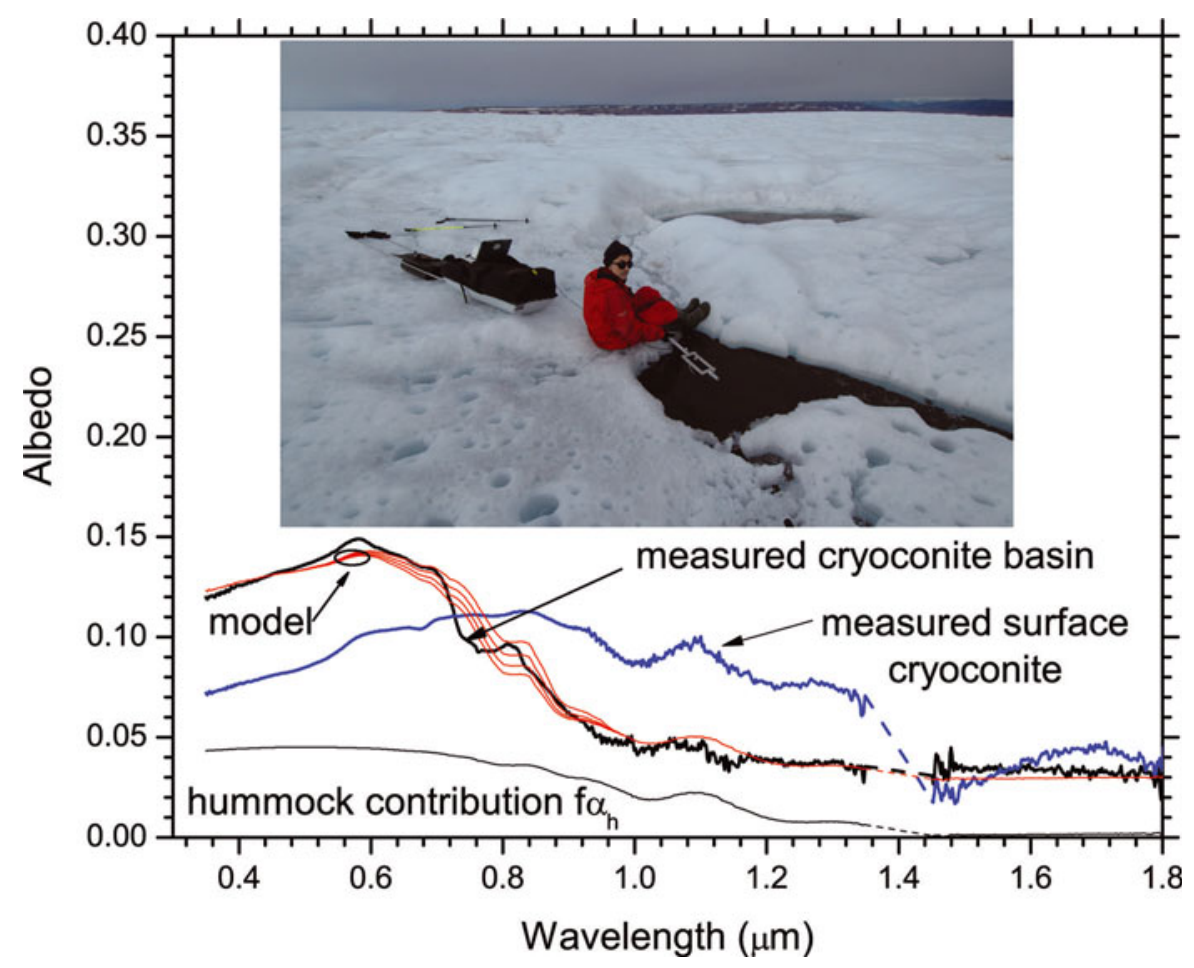

Fig. 7. Explanation of the cryoconite-basin albedo. Looking downward, the diffuser plate was positioned above the cryoconite basin (inset photo). The hemispheric field of view was about $93.5 \%$ cryoconite basin; the remaining $6.5 \%$ was bright hummocky ice surrounding the basin, with spectral albedo $\alpha_{\mathrm{h}}(\lambda)$ as shown in Figure 5. That contribution is plotted here as $f_{\alpha_{\mathrm{h}}}$ with $f=0.065$. Fresnel reflection from the water surface (not shown) is inferred to be $R_{1}=0.033$ as explained in the Appendix, independent of wavelength. The 'measured surface cryoconite' spectrum shown here is the same as in Figure 6, plotted here on an expanded scale. The contributions of surface cryoconite albedo, hummock albedo, Fresnel reflection, and absorption in the basin water above its cryoconite floor are combined in Equations (A5) and (A6); the results are shown in red for four different water depths $(10,12.5,15,17.5 \mathrm{~cm}$; the topmost red curve is for $10 \mathrm{~cm})$. 


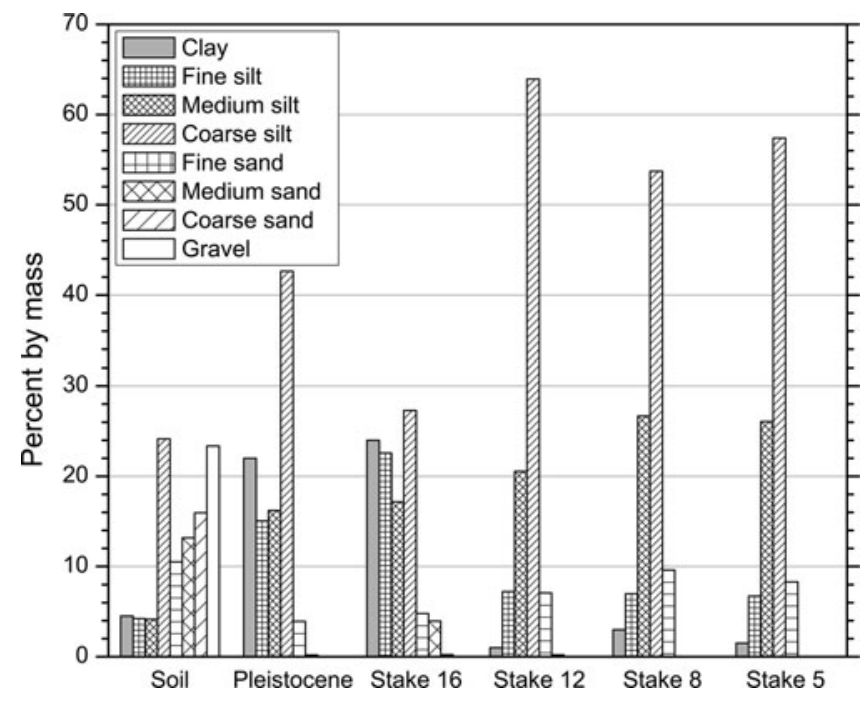

Fig. 8. Particle size distribution of debris on the ice surface (\% by mass). The 'soil' sample is from tundra east of the ice edge. The 'Pleistocene' distribution is a pooled sample from several sites within the Pleistocene ice. Pooling of samples was necessary because each individual sample did not contain enough sediment for analysis. Stake 16 is also in the Pleistocene ice; however, it was sufficiently large to be individually analyzed. Stakes 12,8 and 5 are in Holocene ice, progressing farther from the ice margin. The size categories are as follows: clay, diameter $<2 \mu \mathrm{m}$; fine silt, $2-6 \mu \mathrm{m}$; medium silt, $6-20 \mu \mathrm{m}$; coarse silt, 20-63 $\mu \mathrm{m}$; fine sand, $63-200 \mu \mathrm{m}$; medium sand, 200-600 $\mu \mathrm{m}$; coarse sand, 0.6-2 mm; gravel, $>2 \mathrm{~mm}$.

view. The spectral albedo is reproduced on an expanded scale in Figure 7, together with several components that contribute to the measured albedo, as described in the figure caption and discussed in detail in the Appendix.

\section{COMPOSITION AND CHARACTER OF SURFACE PARTICULATES}

Analysis of the surface sediment collected along the sampling transect involved a multi-proxy approach in which sediment parameters such as organic-inorganic content, bulk mineralogy, clay mineralogy and grain size were quantified using standard techniques. Percentage organic and inorganic matter was obtained by loss-on-ignition (LOI; Brown and Pasternack, 2004), whereby samples were weighed wet, dried overnight at $60^{\circ} \mathrm{C}$, weighed dry, combusted for 6 hours at $600^{\circ} \mathrm{C}$ in a muffle furnace and reweighed. The difference between wet mass and dry mass is the water content, and the difference between dry mass and post-combustion mass is the organic matter content. Bulk and clay-mineral suites were obtained by X-ray diffraction (XRD) using a Philips PW-1050 diffractometer with $\mathrm{Co}-\mathrm{K} \alpha$ radiation. For bulk mineralogy, the soil samples were gently crushed and passed through a $<500 \mu \mathrm{m}$ sieve, whereas sediment collected from the ice surface was centrifuged and air-dried. Clay mineral $(<0.002 \mathrm{~mm})$ determinations were obtained by disintegrating and separating the sample into separate size fractions using a particle-size centrifuge. Oriented specimens were prepared by the pipette method whereby a drop of suspension was dried on a glass plate. Samples were then repeatedly analysed following Mgsaturation, glycerol and K-saturation treatments. Sediment grain size (by mass) was determined using the Andreasen pipette method (Wilson, 1980) based on gravity sedimentation in a $2 \mathrm{mM}$ solution of sodium pyrophosphate.

$L O I$ analysis reveals that the impurities in the cryoconite holes comprise a large ( 95\%) mineralogical component and a smaller organic $(\sim 5 \%)$ component. This value is slightly lower compared to cryoconite samples from northwest Greenland (near Thule), where the organic content comprised $13-20 \%$ of the sample (Gerdel and Drouet, 1960). Regarding mineralogical composition, both XRD and scanning electron microscope analyses show that the impurities are largely quartz and feldspar minerals along with some clay minerals. Both dust samples from snow banks and soil samples collected adjacent to the ice sheet are compositionally similar. Grain-size analysis (Fig. 8) reveals that the impurities near the ice margin on Pleistocene and early Holocene ice are a mixture of clay $(<2 \mu \mathrm{m})$, silt $(2-63 \mu \mathrm{m})$ and sand-sized $(63 \mu \mathrm{m}-2 \mathrm{~mm})$ particles, whereas fine sand $(63-200 \mu \mathrm{m})$ dominates further along the transect. The overall general coarseness of the impurity sediment (i.e. average $\sim 27 \%$ silt and $\sim 7 \%$ fine sand content) suggests short distance transport and thus a local origin (Sun and others, 2002). Only the Pleistocene ice contained a significant fine mode ( $>20 \%$ clay). It is posited
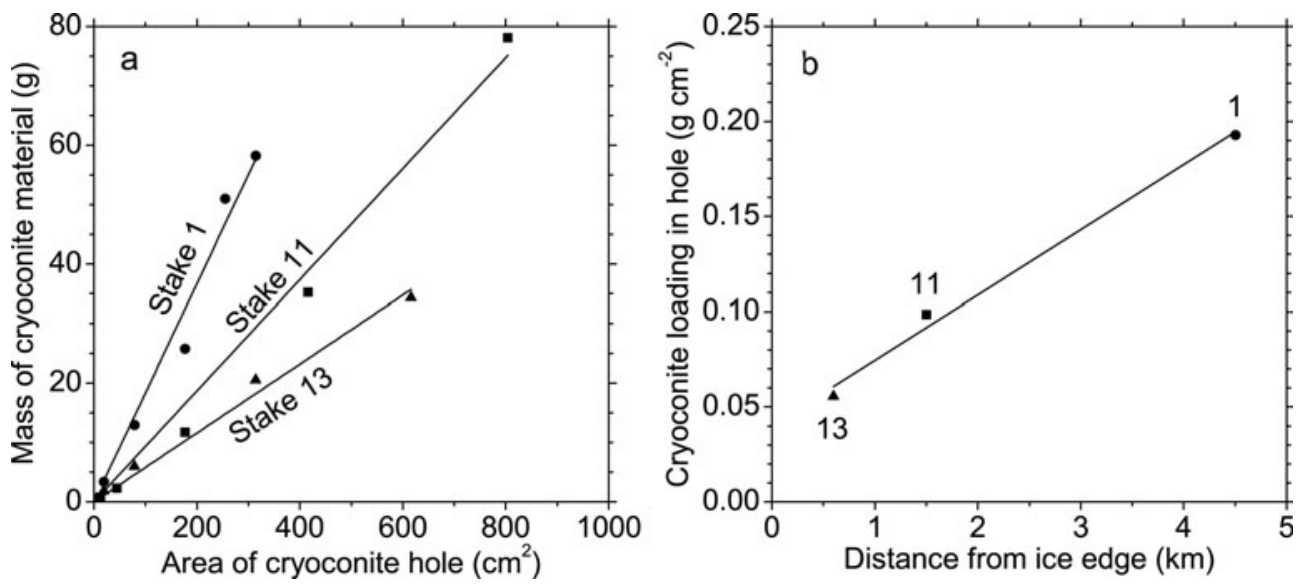

Fig. 9. Dry mass of debris in cryoconite holes at three locations. (a) Mass of cryoconite material (g) vs area of hole $\left(\mathrm{cm}^{2}\right)$. (b) Mass per unit area in cryoconite holes $\left(\mathrm{g} \mathrm{cm}^{-2}\right)$, vs distance from ice edge. The three points represent the three stakes in (a). The values plotted in (b) are the slopes of the lines in (a). 


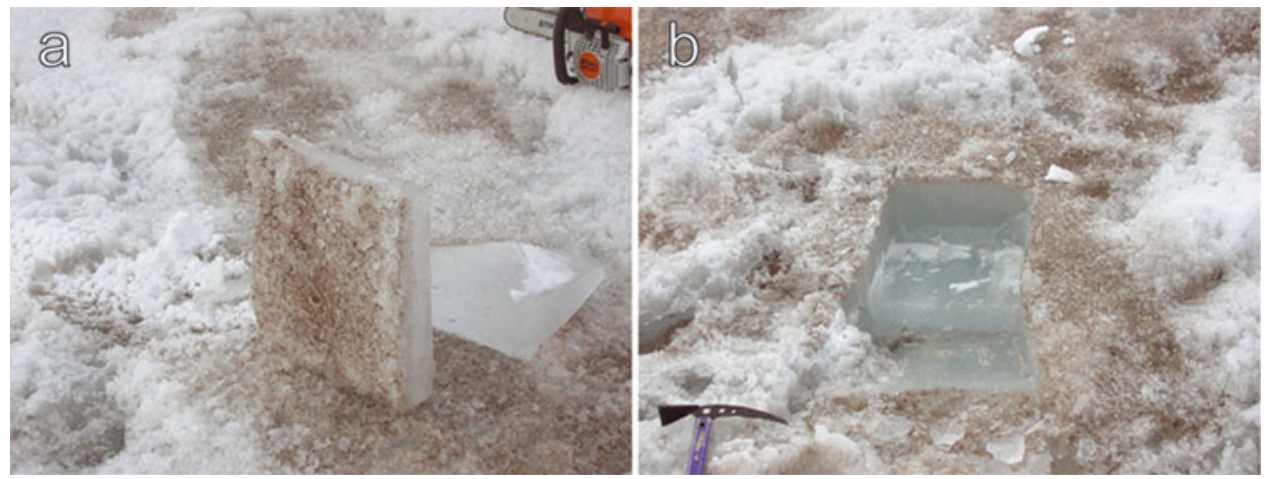

Fig. 10. Ice surface from which a $10 \mathrm{~cm}$ thick block has been removed, showing that nearly all the particles are located at the top surface.

that this fine mode does not have a local source since it is absent from the ice farther from the margin as well as in the soil samples. Its presence in Pleistocene ice and absence in Holocene ice indicates a glacial-interglacial difference in long-range transport of dust (Biscaye and others, 1997).

\section{MASS OF PARTICULATE MATTER IN THE SURFACE ICE}

The mass of impurities in cryoconite holes was measured at three locations along the transect, near stakes 1, 11 and 13 (Fig. 1), covering nearly the full width of exposed Holocene ice. At each of the three sites a wide distribution of cryoconite-hole sizes was sampled. For each hole the diameter was measured and all the particulate matter was sucked out. Each sample was later dried in an oven at $105^{\circ} \mathrm{C}$ for a sufficiently long time to remove all the water, then weighed.

There is only a weak correlation between dry mass and area for all the holes taken together, but good correlation is found for each location separately (Fig. 9a), implying that the dry mass per unit area of a cryoconite hole is independent of the hole diameter. Across the Holocene ice, the dry mass per unit area in cryoconite holes increases with distance from the ice edge (Fig. 9b). The explanation for this behavior is uncertain; perhaps washing by meltwater cleans the ice. Ice closer to the margin experiences more melting, and more meltwater flow from upslope, both of which may help to flush cryoconite material from the ice.

To determine the dry mass on surfaces with uniformly distributed impurities, a different approach was used, whereby an area of $900 \mathrm{~cm}^{2}$ was cut out of the ice using a clean chainsaw. The thickness of each sample was about $10 \mathrm{~cm}$, but the results are insensitive to the thickness because almost all the particulates were coating the top surface of the ice (Fig. 10). Each sample was melted in a pan over a stove, and the particulate impurities collected at the bottom as sediment. This sediment was taken back to the laboratory and dried in the oven. Five samples of Pleistocene ice had loadings of $4-80 \mathrm{~g} \mathrm{~m}^{-2}$, with a median of $40 \mathrm{~g} \mathrm{~m}^{-2}$. Four samples near stake 8 had loadings of 17 and $60 \mathrm{~g} \mathrm{~m}^{-2}$ on hummocks, and 78 and $111 \mathrm{~g} \mathrm{~m}^{-2}$ on nearby dark surfaces. Four samples near stake 1 in the upper ablation zone had the highest loadings, 200-400 $\mathrm{g} \mathrm{m}^{-2}$.

The subsurface ice was also sampled for impurity content, in order to assess whether the surface debris originated as dust deposited on the snow high on the ice sheet and now remains as a lag deposit on the ablating ice after many years of melting. The subsurface ice samples were melted in a microwave oven; the meltwater was then sucked through a $0.4 \mu \mathrm{m}$ Nuclepore filter by means of a partial vacuum from a handpump. The filters were dried and weighed, and the meltwater volume recorded. The impurity content of the ice a few $\mathrm{cm}$ below the surface (at stakes 1,8 and 14) ranged from 2 to $6 \mathrm{mg} \mathrm{L}^{-1}$; the average was $4.3 \mathrm{mg} \mathrm{L}^{-1}$ (equivalent to $3.9 \mathrm{~g} \mathrm{~m}^{-3}$, assuming ice density is $917 \mathrm{~kg} \mathrm{~m}^{-3}$ ). 'Low impurity' surfaces were measured near stakes 1 and 8; they had an average debris cover of $16 \mathrm{~g} \mathrm{~m}^{-2}$, with little variability among the sites. This debris cover would therefore result from ablation of $4 \mathrm{~m}$ of ice of uniform impurity content, if none of it washed away in meltwater streams. At an ablation rate of $\sim 0.6 \mathrm{~m} \mathrm{a}^{-1}$ it would take only 7 years to melt $4 \mathrm{~m}$ of ice. We conclude that ablation of old ice, containing dust from intercontinental transport, could easily account for the observed surface impurity loading in the regions of low impurity. The ice with intermediate and high impurity content may have other contributors; in particular, there is surely a contribution of local dust from the nearby tundra. It is likely that most of the ancient dust has washed away with meltwater since reaching the ablation zone.

\section{SPECULATIONS ABOUT RELATIONS BETWEEN IMPURITY LOADING, FORMATION OF CRYOCONITE HOLES, ALBEDO, AND ABLATION RATES}

Ablation rates at the stakes are shown in Figure 11. Curiously, there is little difference in ablation rate across the Pleistocene/Holocene boundary between stakes 14 and 15 . The average ablation rate was $\sim 2 \mathrm{~cm} \mathrm{~d}^{-1}$, with variations due to patchiness of surface impurity loading and whether the cryoconite material was concentrated into holes. The variables likely to be important for formation of cryoconite holes are particle loading, particle size, ice crystal size and surface slope (Bøggild, 1998; MacDonell and Fitzsimons, 2008). Cryoconite holes apparently form only when the cryoconite loading exceeds a threshold value; this has also been seen on Wright Lower Glacier, McMurdo Dry Valleys, Antarctica (MacDonell and Fitzsimons, 2008). In KPCL the threshold value appears to be about $0.5 \mathrm{~kg} \mathrm{~m}^{-2}$; on Wright Lower Glacier it was a thickness of $2 \mathrm{~mm}$, which corresponds to $\sim 5 \mathrm{~kg} \mathrm{~m}^{-2}$. In regions with impurity content near the threshold value, we find neighboring surfaces with and 


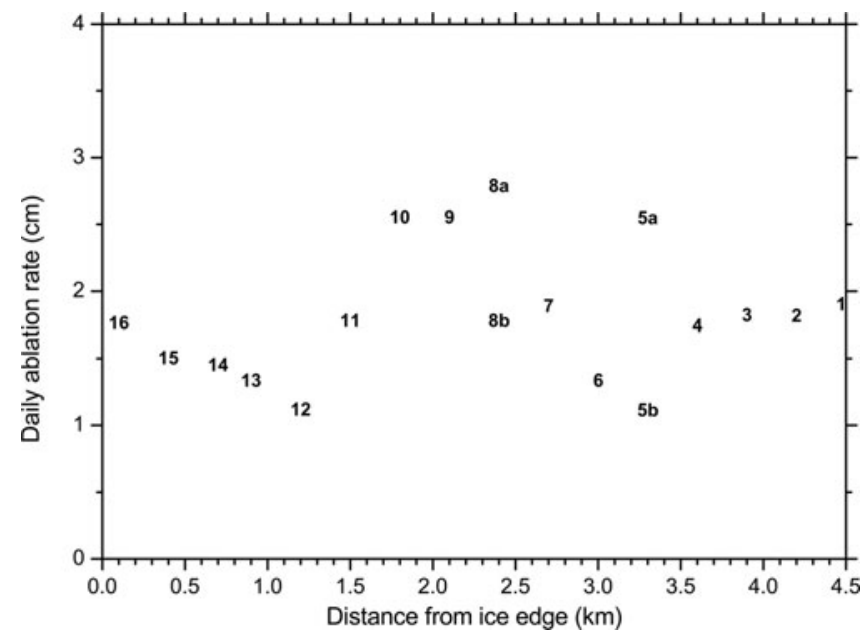

Fig. 11. Ablation rate of ice as a function of distance from the ice edge for the period 28 July-9 August 2006. Each data point is labelled by its stake number. Two stakes were planted at location 8 , on two different surface types; similarly for location 5 . Stakes $5 b$ and $8 \mathrm{~b}$ were in hummocks studded with cryoconite holes; stakes $5 \mathrm{a}$ and 8 a were in adjacent ice with uniform surficial debris. The ice density is $\sim 900 \mathrm{~kg} \mathrm{~m}^{-3}$, so for example $2 \mathrm{~cm} \mathrm{~d}^{-1}$ of ablation corresponds to $18 \mathrm{~mm}$ w.e. $\mathrm{d}^{-1}$.

without holes (e.g. Fig. 3b). This was the situation at stakes 5 and 8 , where a stake was planted in a hummock studded with cryoconite holes (stakes $5 \mathrm{~b}$ and $8 \mathrm{~b}$ ) and another stake planted in adjacent ice with uniform surficial debris (stakes $5 a$ and 8a).

Because local variations of ablation rate are expected to be largely caused by variations of albedo, in Figure 12 we plot the broadband albedo vs impurity loading. The measured points in Figure 12 follow the solid line, with one outlier. The albedo of drained ice of a clean hummock cannot be lower than that of the hummocks containing cryoconite holes, so we also plot a point at $(0.0,0.65)$. The dashed lines are our speculation of the behaviour for impurity loadings not measured. At low impurity loadings $\left(0.0-0.4 \mathrm{~kg} \mathrm{~m}^{-2}\right)$ the albedo should decrease. Then as impurity loading increases, the debris increasingly concentrates into cryoconite holes, hiding itself and raising the albedo. At very high impurity loadings the albedo must decrease again, asymptoting to the value 0.15 characteristic of damp soil (Table 1) or a debris-covered glacier (Higuchi and Nagoshi, 1977; Adhikary and others, 2000).

The outlier in Figure 12 is ice of the upper ablation zone, which has impurity loading within the range that normally forms cryoconite holes, but it has very low albedo because the debris in this ice does not aggregate to form holes. The ice emerging in the upper ablation zone is younger than ice emerging closer to the margin. Cryoconite material cannot move down deeper than solar radiation penetrates. Bøggild (1998) proposed that the absence of cryoconite holes in the dark upper ablation zone was due to the smaller crystal sizes in younger ice, maintaining a high scattering coefficient just below the debris layer and preventing deep penetration of sunlight. However, we have no direct evidence to support or dispute this speculation. The dark upper ablation zone would be worthy of further study, because it seems to be widespread around the margin of the Greenland ice sheet, so it could become important as climatic warming exposes more of it.

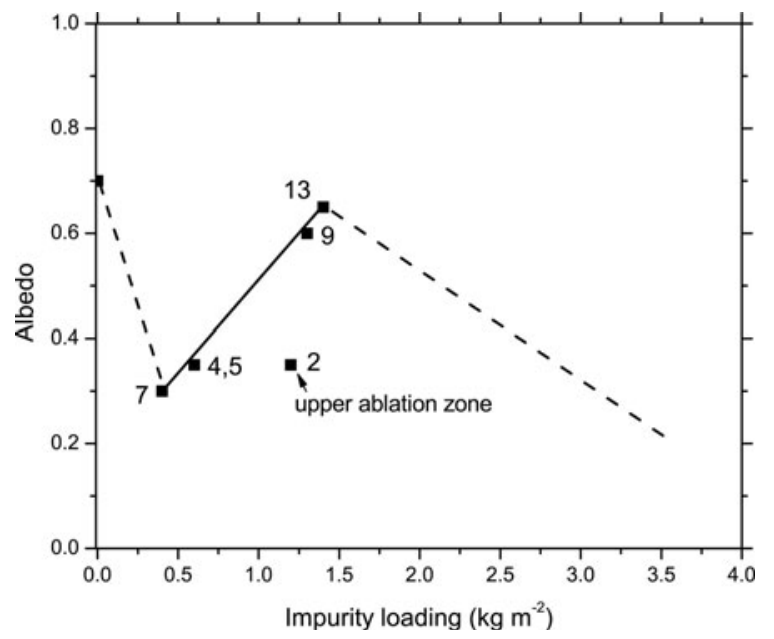

Fig. 12. Effect of impurity content on broadband albedo of ice in the ablation zone. Albedos were obtained as weighted averages of the albedos in Table 1, with weighting factors from Figure $2 \mathrm{~b}$. The points are labelled with corresponding stake numbers. Clean drained ice, as found in hummocks with impurity loading near zero, has albedo 0.7. Small amounts of impurities lower the albedo, but above $\sim 0.5 \mathrm{~kg} \mathrm{~m}^{-2}$ the impurities aggregate, becoming concentrated in cryoconite holes, raising the area-averaged albedo. At impurity contents beyond the highest measured $\left(1.4 \mathrm{~kg} \mathrm{~m}^{-2}\right)$, the albedo is expected to decrease, as shown by the speculative dashed line, asymptoting to the value 0.15 characteristic of damp soil or a debriscovered glacier. The outlier, with lower than expected albedo, is the dark upper ablation zone; it is discussed in the text.

\section{CONCLUSIONS}

Dust deposition on snow over the entire Greenland ice sheet results in small concentrations in the surface snow. The dust is then carried down and outward by ice flow, and much of it is left behind at the surface as the ice melts in the ablation zone. In northeast Greenland the ablation zone is narrow, making it convenient for study.

Measurements of albedo, impurity content and ablation rates lead us to conclude that the process of cryoconite-hole formation is crucially important to the ablation rates. The albedo of the ice is reduced by the presence of soil dust on the surface, but when the dust aggregates and descends into cryoconite holes it hides itself from sunlight, raising the albedo dramatically. The albedo for ice uniformly covered with debris was 0.2-0.4, whereas for ice with cryoconite holes it was 0.6 , even though the ice with cryoconite holes contained more debris per unit area. The consequence of this albedo contrast was apparent in the difference of ablation rates at nearby stakes that were planted in ice of similar debris content that was either uniformly distributed or concentrated in holes.

Most of the cryoconite holes are narrow and vertical, about $15-30 \mathrm{~cm}$ deep. Albedos estimated from nadir-viewing satellites such as Landsat will therefore be biased low in regions of cryoconite holes. Large cryoconite 'basins' also occur, with albedo $\sim 0.1$.

The mineralogical composition of the cryoconite material is comparable with that of the surrounding soils and with dust on a snowdrift in front of the ice margin, implying that much of the material is derived from local sources. However, the fine mode (clay) is prevalent in the oldest ice but not in the nearby soil, suggesting that the 
clay resulted from dust deposition during Pleistocene glaciation.

There appears to be a minimum impurity loading of about $0.5 \mathrm{~kg} \mathrm{~m}^{-2}$ necessary to form cryoconite holes. Within the Holocene ice, the cryoconite loading increases with distance from the margin for unknown reasons, perhaps because the younger ice has not yet been exposed to much washing by meltwater streams. However, the upper ablation zone is peculiar: the dust concentration is in the range expected to form cryoconite holes, yet it remains uniformly distributed, so the ice is much darker. This anomalous surface is actually widespread in area and therefore important for the climate, but we do not have an explanation for it. The dust size distributions here do not differ from those in lower regions. In future investigations it will be good to measure ice crystal sizes in the regions with and without holes, and to observe the upper ablation zone for an entire summer season.

\section{ACKNOWLEDGEMENTS}

We thank J. Haffey of Ken Borek Air for his persistence in finding a suitable landing strip at our field site and his expertise in landing the Twin Otter there. Two anonymous reviewers provided helpful comments. This research was supported by the Danish Polar Center, the University Centre in Svalbard (UNIS), the Geological Survey of Denmark and Greenland (GEUS), the Clean Air Task Force, the Oak Foundation, and US National Science Foundation grant ARC-0612636.

\section{REFERENCES}

Adhikary, S., M. Nakawo, K. Seko and B. Shakya. 2000. Dust influence on the melting process of glacier ice: experimental results from Lirung Glacier, Nepal Himalayas. IAHS Publ. 264 (Symposium at Seattle 2000 - Debris-Covered Glaciers), $43-52$.

Ambach, W. and G. Markl. 1983. Untersuchungen zum Strahlungshaushalt in der Akkumulationszone des grönländischen Inlandeises (Station Carrefour $69^{\circ} 49^{\prime} 25^{\prime \prime} \mathrm{N}, 47^{\circ} 25^{\prime} 57^{\prime \prime} \mathrm{W}, 1850 \mathrm{~m}$ ). Medd. Grønl., 187(6).

Bader, H. 1961. The Greenland ice sheet. CRREL Monogr. I-B2.

Benson, C.S. 1960. Stratigraphic studies in the snow and firn of the Greenland ice sheet. (PhD thesis, California Institute of Technology.)

Biscaye, P.E. and 6 others. 1997. Asian provenance of glacial dust (stage 2) in the Greenland Ice Sheet Project 2 ice core, Summit, Greenland. J. Geophys. Res., 102(C12), 26,765-26,781.

Bøggild, C.E. 1998. Different melt regimes indicated by surface albedo measurements at the Greenland ice sheet margin application of TM image. EARSeL Adv. Remote Sens., Yearbook 1997, 5, 82-88.

Bøggild, C.E., H. Oerter and T. Tukiainen. 1996. Increased ablation of Wisconsin ice in eastern north Greenland: observations and modelling. Ann. Glaciol., 23, 144-148.

Bohren, C.F. 1987. Multiple scattering at the beach. In Clouds in a glass of beer: simple experiments in atmospheric physics. New York, Wiley, 113-119.

Box, J.E. and 8 others. 2006. Greenland ice sheet surface mass balance variability (1988-2004) from calibrated Polar MM5 output. J. Climate, 19(12), 2783-2800.

Brandt, R.E., S.G. Warren, A.P. Worby and T.C. Grenfell. 2005. Surface albedo of the Antarctic sea ice zone. J. Climate, 18(17), 3606-3622.
Brown, K.J. and G.B. Pasternack. 2004. The geomorphic dynamics and environmental history of an upper deltaic floodplain tract in the Sacramento-San Joaquin Delta, California, USA. Earth Surf. Process. Landf., 29(10), 1235-1258.

Condit, H.R. 1970. The spectral reflectance of American soils. Photogramm. Eng., 36(9), 955-966.

De Angelis, M., J.P. Steffensen, M. Legrand, H. Clausen and C. Hammer. 1997. Primary aerosol (sea salt and soil dust) deposited in Greenland ice during the last climatic cycle: comparison with East Antarctic records. J. Geophys. Res., 102(C12), 26,681-26,698.

Duynkerke, P.G. and M.R. van den Broeke. 1994. Surface energy balance and katabatic flow over glacier and tundra during GIMEx-91. Global Planet. Change, 9(1-2), 17-28.

Gajda, R.T. 1958. Cryoconite phenomena on the Greenland Ice Cap in the Thule area. Can. Geogr., 3(12), 35-44.

Gerdel, R.W. and F. Drouet. 1960. The cryoconite of the Thule area, Greenland. Trans. Am. Microsc. Soc., 79, 256-272.

Grenfell, T.C. and D.K. Perovich. 1981. Radiation absorption coefficients of polycrystalline ice from 400-1400 nm. J. Geophys. Res., 86(C8), 7447-7450.

Grenfell, T.C. and D.K. Perovich. 1984. Spectral albedos of sea ice and incident solar irradiance in the southern Beaufort Sea. J. Geophys. Res., 89(C3), 3573-3580.

Grenfell, T.C., S.G. Warren and P.C. Mullen. 1994. Reflection of solar radiation by the Antarctic snow surface at ultraviolet, visible, and near-infrared wavelengths. J. Geophys. Res., 99(D9), $18,669-18,684$.

Greuell, W. 2000. Melt-water accumulation on the surface of the Greenland ice sheet: effect on albedo and mass balance. Geogr. Ann., Ser. A, 82(4), 489-498.

Greuell, W. and W.H. Knap. 2000. Remote sensing of the albedo and detection of the slush line on the Greenland ice sheet. J. Geophys. Res., 105(D12), 15,567-15,576.

Greuell, J.W. and T. Konzelmann. 1994. Numerical modeling of the energy balance and the englacial temperature of the Greenland ice sheet: calculations for the ETH-Camp location (West Greenland, $1155 \mathrm{~m}$ a.s.l.). Global Planet. Change, 9(1-2), 91-114.

Gribbon, P.W.F. 1979. Cryoconite holes on Sermikavsak, West Greenland. J. Glaciol., 22(86), 177-181.

Hale, G.M. and M.R. Query. 1973. Optical constants of water in the 200-nm to 200- $\mu \mathrm{m}$ wavelength region. Appl. Opt., 12(3), $555-563$.

Hanna, E., P. Huybrechts, I. Janssens, J. Cappelen, K. Steffen and A. Stephens. 2005. Runoff and mass balance of the Greenland ice sheet: 1958-2003. J. Geophys. Res., 110(D13), D13108. (10.1029/2004JD005641.)

Henneken, E.A.C., N.J. Bink, H.F. Vugts, F. Cannemeijer and A.G.C.A. Meesters. 1994. A case study of the daily energy balance near the equilibrium line on the Greenland ice sheet. Global Planet. Change, 9(1-2), 69-78.

Herman, G.F. and J.A. Curry. 1984. Observational and theoretical studies of solar radiation in Arctic stratus clouds. J. Climate Appl. Meteorol., 23(1), 5-24.

Higuchi, K. and A. Nagoshi. 1977. Effect of particulate matter in surface snow layers on the albedo of perennial snow patches. IAHS Publ. 118 (Symposium at Grenoble 1975 - Isotopes and Impurities in Snow and Ice), 95-97.

Holmlund, P. and P. Jansson. 2003. Glaciologi. Stockholm, Vetenskapsrådet \& Stockholms Universitet.

Kayser, O. 1928. The inland ice. In Vahl, M., G.C. Amdrup, L. Bobé and Ad.S. Jensen, eds. Greenland. Vol. I. Copenhagen, C.A. Reitzel, 381-384.

Kindel, B.C., Z. Qu and A.F.H. Goetz. 2001. Direct solar spectral irradiance and transmittance measurements from 350 to 2500 nm. Appl. Opt., 40(21), 3483-3494.

Knap, W.H. and J. Oerlemans. 1996. The surface albedo of the Greenland ice sheet: satellite-derived and in situ measurements in the Søndre Strømfjord area during the 1991 melt season. J. Glaciol., 42(141), 364-374. 
Konzelmann, T. and R.J. Braithwaite. 1995. Variations of ablation, albedo and energy balance at the margin of the Greenland ice sheet, Kronprins Christian Land, eastern north Greenland. J. Glaciol., 41(137), 174-182.

Krabill, W. and 12 others. 2004. Greenland Ice Sheet: increased coastal thinning. Geophys. Res. Lett., 31(24), L24402. (10.1029/ 2004GL021533.)

Lliboutry, L. 1964. Traité de glaciologie. Tome I. Paris, Masson.

MacDonell, S. and S. Fitzsimons. 2008. The formation and hydrological significance of cryoconite holes. Progr. Phys. Geogr., 32(6), 595-610.

McClatchey, R.A., R.W. Fenn, J.E.A. Selby and J.S. Garing. 1972. Optical properties of the atmosphere. Third edition. Hanscom, MA, Air Force Cambridge Research Laboratory. (AFCRL Rep. 72-0497.)

Mullen, P.C. and S.G. Warren. 1988. Theory of optical properties of lake ice. J. Geophys. Res., 93(D7), 8403-8414.

Oerter, H., C.E. Bøggild, F. Jung-Rothenhäusler and N. Reeh. 1995. Glaciological fieldwork in Kronprins Christian Land: results from 1994. Geol. Surv. Greenland Open File Ser. 95/5, 97-105.

Paterson, W.S.B. 1994. The physics of glaciers. Third edition. Oxford, etc., Elsevier.

Rignot, E. and P. Kanagaratnam. 2006. Changes in the velocity structure of the Greenland Ice Sheet. Science, 311(5673), 986-990.

Serreze, M. and R.G. Barry. 2005. The Arctic climate system. Cambridge, etc., Cambridge University Press.

Sharp, R.P. 1949. Studies of superglacial debris on valley glaciers. Am. J. Sci., 247(5), 289-315.

Sun, D. and 6 others. 2002. Grain-size distribution function of polymodal sediments in hydraulic and aeolian environments, and numerical partitioning of the sedimentary components. Sediment. Geol., 152(3-4), 263-277.

Thorsteinsson, T., J. Kipfstuhl and H. Miller. 1997. Textures and fabrics in the GRIP ice core. J. Geophys. Res., 102(C12), $26,583-26,599$.

Tsay, S.C. and K. Jayaweera. 1984. Physical characteristics of Arctic stratus clouds. J. Climate Appl. Meteorol., 23(4), 584-596.

Twomey, S.A., C.F. Bohren and J.L. Mergenthaler. 1986. Reflectance and albedo differences between wet and dry surfaces. Appl. Opt., 25(23), 431-437.

Van de Wal, R.S.W. and 11 others. 1995. Mass balance measurements in the Søndre Strømfjord area in the period 1990-1994. Z. Gletscherkd. Glazialgeol., 31(1-2), 57-63.

Van den Broeke, M., P. Smeets, J. Ettema and P.K. Munneke. 2008. Surface radiation balance in the ablation zone of the west Greenland ice sheet. J. Geophys. Res., 113(D13), D13105. (10.1029/2007JD009283.)

Warren, S.G. and R.E. Brandt. 2008. Optical constants of ice from the ultraviolet to the microwave: a revised compilation. J. Geophys. Res., 113(D14), D14220. (10.1029/2007JD009744.)

Weidick, A. 1995. Greenland. In Williams, R.S. and J. Ferrigno, eds. Satellite image atlas of glaciers of the world. Denver, CO, US Geological Survey, C1-C105. (USGS Professional Paper 1386-C.)

Weidick, A., C.E. Böggild and N.T. Knudsen. 1992. Glacier inventory and atlas of West Greenland. Rapp. Grønl. Geol. Unders. 158.

Wilson, R. 1980. Reference materials of defined particle size certified recently by the community bureau of reference of the European Economic Community. Powder Tech., 27(1), 37-43.

Wiscombe, W.J., R.M. Welch and W.D. Hall. 1984. The effects of very large drops on cloud absorption. Part I. Parcel models. J. Atmos. Sci., 41(8), 1336-1355.

Zwally, H.J., W. Abdalati, T. Herring, K. Larson, J. Saba and K. Steffen. 2002. Surface melt-induced acceleration of Greenland ice-sheet flow. Science, 297(5579), 218-222.

Zwally, H.J. and 7 others. 2005. Mass changes of the Greenland and Antarctic ice sheets and shelves and contributions to sealevel rise: 1992-2002. J. Glaciol., 51(175), 509-527.

\section{APPENDIX}

\section{SPECTRAL ALBEDO OF A CRYOCONITE BASIN}

Following Mullen and Warren (1988), who made a similar exposition for lake ice, the upward flux $\left(F_{\mathrm{u}}\right)$ from a shallow basin with a reflective floor consists of several components

$$
F_{\mathrm{u}}=\sum_{i} F_{i}
$$

listed as follows.

1. External specular reflection $(i=1)$ :

$$
F_{1}=R_{1} F_{\mathrm{d}}
$$

where $F_{\mathrm{d}}$ is the solar radiation incident from above (diffuse under overcast cloud during the measurement) and $R_{1}$ is the external specular reflection coefficient (air to water).

2. Transmission through the water, reflection by the floor, transmission back up through the water and refraction into the air $(i=2)$ :

$$
F_{2}=F_{\mathrm{d}}\left(1-R_{1}\right) t_{\mathrm{d}} R_{\mathrm{b}} t_{\mathrm{u}}\left(1-R_{2}\right),
$$

where $t_{\mathrm{d}}$ is the downward transmission through water, $R_{\mathrm{b}}$ is the reflectance of the bottom (cryoconite floor), $t_{\mathrm{u}}$ is the upward transmission through water and $R_{2}$ is the internal reflection coefficient (water to air). We take $R_{\mathrm{b}}$ to be the spectral albedo of damp cryoconite material ('surface cryoconite' in Figs 5 and 6). The transmittances can be expressed as $t_{\mathrm{d}} \approx \exp \left(-k_{\mathrm{w}} d \sec \theta_{\mathrm{d}}\right)$ and $t_{\mathrm{u}} \approx \exp \left(-k_{\mathrm{w}} d \sec \theta_{\mathrm{u}}\right)$, where $d$ is the water depth, $k_{\mathrm{w}}$ is the spectral absorption coefficient of water (Hale and Query, 1973), $\theta_{d}$ is the effective zenith angle of downward diffuse radiation in the water (concentrated toward the normal because of refraction) and $\theta_{\mathrm{u}}$ is the effective zenith angle of radiation reflected from the floor. Since $R_{\mathrm{b}}$ is small, $t_{\mathrm{d}}$ and $t_{\mathrm{u}}$ need not be highly accurate, so we approximate $\sec \theta_{\mathrm{d}} \approx \sec \theta_{\mathrm{u}} \approx 2$.

3. Transmission through the water, reflection by the floor, transmission back up through the water, internal reflection from the water/air interface back down into the water, reflection by the floor, transmission through the water, and refraction into the air $(i=3)$ :

$$
\begin{aligned}
F_{3} & =F_{\mathrm{d}}\left(1-R_{1}\right) t_{\mathrm{d}} R_{\mathrm{b}} t_{\mathrm{u}} R_{2} t_{\mathrm{d}} R_{\mathrm{b}} t_{\mathrm{u}}\left(1-R_{2}\right) \\
& =F_{2} R_{2} t_{\mathrm{d}} R_{\mathrm{b}} t_{\mathrm{u}} .
\end{aligned}
$$

4. The remaining terms $(i=4,5, \ldots)$ contributing to $F_{\mathrm{u}}$ are identical to $F_{3}$ but multiplied by higher powers of $R_{2} t_{\mathrm{d}} R_{\mathrm{b}} t_{\mathrm{u}}$, corresponding to multiple reflections of radiation across the water layer. The basin albedo $\alpha_{\mathrm{b}}=F_{\mathrm{u}} / F_{\mathrm{d}}$ is thus an infinite series, which can be summed as

$$
\alpha_{\mathrm{b}}=R_{1}+\frac{\left(1-R_{1}\right) t_{\mathrm{d}} R_{\mathrm{b}} t_{\mathrm{u}}\left(1-R_{2}\right)}{\left(1-R_{2} t_{\mathrm{d}} R_{\mathrm{b}} t_{\mathrm{u}}\right)} .
$$

As shown in the inset of Figure 7, the downward-looking hemispheric field of view includes not only the cryoconite basin but also some brighter hummock ice around the periphery. The observed albedo $\alpha_{\mathrm{ob}}$ is a weighted average of the basin albedo $\alpha_{\mathrm{b}}$ and the hummock albedo $\alpha_{\mathrm{h}}$ :

$$
\alpha_{\mathrm{ob}}=f \alpha_{\mathrm{h}}+(1-f) \alpha_{\mathrm{b}}
$$

where $f$ is the fraction of the field of view occupied by hummocks, estimated below as $\sim 6.5 \%$. The internal 
reflectance $R_{2}$ was calculated from the Fresnel equations to be 0.22 , nearly independent of wavelength across the solar spectrum. The external Fresnel reflectance $R_{1}$ would be 0.07 if the incident light were diffuse from the entire hemisphere. However, part of the sky hemisphere was blocked by hummocks. We therefore did not calculate $R_{1}$ but instead chose its value to best fit the measured albedo at 1.2-1.8 $\mu \mathrm{m}$, where Fresnel reflection is the only contributor to the basin albedo, obtaining
$R_{1}=0.033$. The hummock fraction was then adjusted to obtain the best fit between modeled and observed albedo at visible wavelengths $(0.35-0.6 \mu \mathrm{m})$, where water is non-absorptive, obtaining $f=0.065$. The water depth $d$ was not measured, but the model albedo is not very sensitive to $d$. Calculations are shown for four values of $d$ from 10 to $17.5 \mathrm{~cm}$. Figure 7 shows that $f \alpha_{\mathrm{h}}$ contributes approximately $0.04-0.05$ to the measured albedo at visible wavelengths.

MS received 19 February 2009 and accepted in revised form 30 November 2009 